\title{
PRÁTICAS DE GESTÃO: UM ESTUDO DE CASO NA ESCOLA MUNICIPAL SANTOS ANJOS/RS
}

http://dx.doi.org/10.5902/2318133834029

\author{
Rosangela Fritsch \\ Angela Thums ${ }^{2}$
}

\begin{abstract}
Resumo
Este artigo resulta de uma pesquisa sobre gestão escolar com foco na reflexão sobre práticas que vêm sendo adotadas à luz de políticas educacionais. Buscou-se compreender quais variáveis têm contribuído para que a Escola Municipal Santos Anjos venha atingindo Ideb acima das metas projetadas. Configura-se numa pesquisa qualitativa, com a coleta de dados sendo feita por meio de observação, entrevistas e documentos submetidos à análise de conteúdo. Como resultado algumas variáveis emergiram como significativas influenciando e contribuindo para a qualidade do ensino na escola estudada: cultura da comunidade, cultura da escola e as práticas da gestão.

Palavras-chave: gestão escolar; cultura da escola e da comunidade; indicadores de qualidade.
\end{abstract}

\section{MANAGEMENT PRACTICES: A CASE STUDY AT THE MUNICIPAL SCHOOL SANTOS ANJOS IN RS}

\section{Abstract}

This article results from a research conducted on school management focused on the reflection about practices that has been adopted in light of educational policies. It seeks to understand which variables has contributed to the Municipal School Santos Anjos achieve Ideb above projected goals. As a qualitative research, its data collection was conducted via observation, interviews and documents submitted to content analysis. As a result, some significant variables emerged affecting and contributing to the quality of teaching in the school considered: community's culture, school's culture, and management practices.

Key-words: school management; school and city culture; quality index.

\footnotetext{
1 Universidade do Vale do Rio dos Sinos, Brasil. E-mail: rosangelaf@unisinos.br.

${ }^{2}$ Colégio Notre Dame de Passo Fundo, Brasil. E-mail: angela@notredame.org.br.

\begin{tabular}{|l|l|l|l|l|l|}
\hline Regae: Rev. Gest. Aval. Educ. & Santa Maria & v. 8 & n. 17 & Pub. contínua 2019 & p. 1-16 \\
\hline
\end{tabular}
}




\section{Introdução}

este artigo apresenta-se um estudo sobre gestão escolar trazendo à tona uma reflexão sobre aspectos que estão implicados com melhores resultados na perspectiva de alguns indicadores educacionais. $O$ objetivo foi compreender que variáveis têm contribuído para que a Escola Municipal Santos Anjos EMSA -, de educação básica, situada no Rio Grande do Sul, venha atingindo Índice de Desenvolvimento da Educação Básica - Ideb - acima das metas projetadas, considerando o contexto atual das políticas de avaliação em larga escala e as repercussões dos seus resultados no cenário educacional e, também, os resultados de outros municípios.

Entre os anos de 2011 e 2013 verificou-se que o ldeb da rede municipal do Município de Nova Boa Vista/RS vinha superando as metas projetadas pelo Ministério da Educação e Cultura (Brasil, 2014). De modo geral, as notas desse município apresentavam-se superiores às do Estado do Rio Grande do Sul e de alguns municípios com características similares, comparando-se indicadores sociais, demográficos, educacionais, políticos e econômicos.

No percurso de desenvolvimento dessa pesquisa algumas questões foram norteadoras: há um referencial de qualidade da educação e práticas de gestão que fazem com que determinadas escolas atinjam uma excelência nos resultados de índices educacionais, comparadas a outras que estariam em condições sociais similares? Por que alunos de determinadas escolas públicas conseguem atingir melhor desempenho em avaliações externas? A escola, por meio da sua dinâmica organizacional, pode contribuir para a melhoria da qualidade educacional dos seus alunos? Quais práticas educativas podem ser identificadas como desdobramentos relacionados aos processos de gestão escolar da escola pública?

A gestão da escola tem sido apresentada por Libâneo (2012) como uma atividade de mediação dos processos de ensino, contribuindo para a melhoria dos resultados das organizações escolares. Dessa forma, a gestão escolar coloca se como uma variável relevante e que contribui para o desempenho das instituições de ensino.

Neste estudo, faz-se necessário situar, pela sua interferência na gestão da escola, as políticas educacionais e a influência internacional nas políticas nacionais, regionais e locais, em particular as políticas de avaliação em larga escala que têm ocupado um papel central nas políticas públicas de educação no Brasil. Por seu intermédio tem-se pretendido diagnosticar o nível de aprendizagem dos alunos para compreender as realidades educacionais e, com isso, re-formular planos e programas que, definitivamente, impactem na organização da gestão pedagógica das unidades escolares.

Têm-se enfatizado as políticas educacionais no Brasil, sobretudo a partir da década de 1990, como um fenômeno no campo teórico/prático servindo como meio de materialização, no âmbito das instituições de ensino, dos objetivos e metas concebidas. Encontra-se nessas políticas o discurso da modernização dos processos de gestão da educação, da diversificação, da competitividade, da produtividade, da eficiência e da qualidade dos sistemas educativos da escola e do ensino, conforme Santos (2009), Afonso (2010), Maués (2003), Silva (2002) e Fonseca (1998).

Ao mencionar a qualidade na educação é interessante considerar não somente os processos de ensino e aprendizagem, como também a qualidade social, cultural e ambiental da educação, que valoriza, além do conhecimento simbólico, o sensível e o

\begin{tabular}{|l|l|l|l|l|l|}
\hline Regae: Rev. Gest. Aval. Educ. & Santa Maria & v. 8 & n. 17 & Pub. contínua 2019 & p. 1-16 \\
\hline
\end{tabular}


técnico, conforme Fernandes (2007), Freitas (2004, 2007), Correia (2010a, 2010b), Freitas (2012), Werle $(2010,2012)$ e Souza e Oliveira (2003). Na educação a qualidade está ligada diretamente ao bem-viver de todas as nossas comunidades, a partir da comunidade escolar.

A produção acadêmica brasileira sobre gestão escolar, qualidade na educação básica, avaliação externa, Ideb, educação básica e indicadores educacionais abordam e problematizam temas como a influência da equipe gestora no plano e na ação da escola e o papel do gestor escolar (Aguiar, 2009; Caldas, 2009; Dantas, 2011; Santos, 2009); as metodologias de gestão e avaliação (Dublante, 2009; Wiebusch, 2011; Rosa, 2011); a gestão da escola e as políticas de avaliação externa e qualidade do ensino. (Garcia, 2010; Martins, 2010).

Aguiar (2009) aponta para a concepção e operação das políticas educacionais, no que se refere à gestão educacional em seu caráter democrático. Por sua vez, Caldas (2009) apresenta algumas contribuições no tocante à forma de participação da comunidade no processo de gestão escolar, em especial no projeto político-pedagógico, analisando essa participação à luz da gestão democrática do ensino público, firmada nos princípios e nas diretrizes da educação nacional. Dantas (2011) destaca as implicações do plano de trabalho apresentado pelos diretores no efetivo desenvolvimento das atividades da gestão escolar e sobre sua utilização no cotidiano escolar. Santos (2009) apresenta a gestão escolar como uma organização cultural que está impregnada de valores, rituais, práticas e relações de poder.

A qualidade da gestão escolar é entendida como responsabilidade do diretor da escola e sua equipe, dentro do plano de ação da escola, diferenciando-se da gestão educacional, que tem a ver com as responsabilidades dos governos e se expressa na organização dos sistemas de ensino, em todos os níveis (Rosa, 2011). Dublante (2009) analisa as práticas de gestão nas escolas públicas tendo como parâmetro a análise do PPP, enquanto que para Garcia (2010), na percepção da equipe gestora e dos professores, dinamizam o trabalho pedagógico, a gestão da escola, tendo em vista as políticas de avaliação externa e a necessária qualidade do ensino. Martins (2010) aborda a avaliação externa como fonte de análise do desempenho escolar, tendo na escola, entre seus gestores, o coordenador pedagógico incumbido de utilizar os resultados da avaliação para reverter o quadro atual em que se encontra a educação nacional.

Para Wiebusch (2011) os fatores e as ações que fizeram com que duas escolas, situadas em dois municípios do Vale do Taquari, no Rio Grande do Sul, ficassem entre as cem melhores escolas estaduais, no Sistema de Rendimento de Avaliação Escolar do Rio Grande do Sul foram: o trabalho coletivo; a infraestrutura das escolas; o professor gestor do processo educacional e o aluno com desejo de progredir e construir o conhecimento dentro e fora da escola.

Tendo em vista que o Brasil é um país com vasta dimensão geográfica e diversidade cultural, uma lista de fatores gerais pode não servir para comunidades tão peculiares sendo pertinente investigar o que as escolas, consideradas bem-sucedidas segundo os sistemas de avaliação em larga escala, apresentam de diferenciais em suas práticas de gestão. 


\section{Percurso metodológico}

As questões da pesquisa foram construídas conforme Szymanski (2011) e Triviños (1987), dando centralidade aos processos de gestão da escola, de qualidade da educação e do Ideb, dialogando com os sujeitos da pesquisa de forma a compor elementos que permitiram a compreensão dos dados coletados e a elaboração das análises (Bardin, 2011).

Escolheu-se a abordagem qualitativa que envolve a obtenção de dados descritivos, adquiridos no contato direto do pesquisador com a situação estudada, havendo também a preocupação de retratar a perspectiva dos participantes na perspectiva de Chizzotti (2003), Lüdke e André (1986), André (2013), Martins (2008), Bodgan e Biklein (1994).

As estratégias da produção de dados utilizadas foram entrevistas, análise documental e observação. O primeiro movimento foi de observação do contexto da Escola Municipal Santos Anjos, utilizando um diário de campo como ferramenta para compor os registros que são evidenciados como registros de diário de campo.

As primeiras impressões foram produzidas durante as diversas visitas informais realizadas na escola, o que significou uma aproximação às pessoas em seu local de trabalho, aceitando o convite de convivência com a comunidade escolar no tempo em que se esteve presente, buscando captar dados sobre como se localizam e se movimentam no cotidiano. Os registros referem-se às percepções e observações durante o tempo de permanência no campo empírico, no contato direto com gestores, professores, funcionários, alunos e familiares na informalidade da entrada e saída, do intervalo, do lanche, dos afazeres dos funcionários, da presença das religiosas, entre outros.

As entrevistas foram realizadas com cinco gestores de diferentes setores: direção da escola, coordenação pedagógica da Secretaria Municipal de Educação, vice-direção e secretária escolar, coordenação pedagógica do ensino fundamental I e II e coordenação pedagógica da educação infantil. Estes foram pertinentes na produção dos dados da pesquisa pela possibilidade de, no diálogo, na relação face a face, ser possível uma compreensão - mais aprofundada e transversal - das suas atuações como gestores. Pelos relatos da vida profissional foi possível um melhor conhecimento sobre quem são eles, que representações têm de si, seus sonhos, o que pensam, e ainda sobre os seus fazeres e saberes profissionais. Conforme Brandão (2003) a entrevista é uma conversa e que toda a conversa é um desafio ao diálogo aberto com o outro, e não apenas um controle sistemático da fala de outro, segundo os usos dos interesses científicos sobre o outro e através do outro.

Em termos de perfil os sujeitos da pesquisa constituem um grupo homogêneo em relação à formação inicial, sendo licenciados em Letras, Pedagogia, Ciências, Matemática e apenas um com bacharelado em Psicologia. É uma equipe de gestores relativamente jovens, do sexo feminino e com faixa etária entre 35 e 51 anos. Quanto à formação continuada é interessante observar que praticamente todos as gestores possuem duas pós-graduações. As G1, G2, G3, G4 e G5, conforme são referidas no texto, possuem pósgraduação em Gestão Escolar ou Supervisão e Orientação Escolar, sendo este um aspecto comum aos gestores desta escola. Além dessa formação elas têm aperfeiçoamento específico na sua área: a G3 e a G4 possuem pós-graduação em Psicopedagogia, enquanto que a G3 está cursando pós-graduação em Psicologia com enfoque clínico, e a G5 possui pós-graduação em Educação Infantil e Anos Iniciais. 
Na pesquisa documental utilizou-se o PPP da escola, o livro Tombo I da Paróquia Nossa Senhora dos Navegantes e o registro deixado pelo padre Davi Schwantes sobre a idealização da escola e a obra Escola Estadual de Ensino Médio Antônio Mathias Anschau: Nova Boa Vista: histórias e memórias (Anschau, 2012). Os documentos foram se compondo a partir dos dados coletados nas observações e entrevistas. Inicialmente, a análise limitar-se-ia ao PPP da escola. Contudo, a relevância da história e da cultura da comunidade como elemento determinante na e da gestão da escola indicou uma mudança no percurso metodológico planejado.

\section{A dimensão da cultura na comunidade e na escola}

A dimensão da cultura da comunidade foi emergindo no processo de produção de dados como influenciando fortemente a gestão da e na escola. Esta seção apresenta as implicações da cultura com os processos de gestão na e da escola tomando como referência alguns conceitos, tais como: cultura escolar, história das instituições escolares, elementos identitários e tendo como interlocutores Julia (2001), Botelho (2001), Lück (2011), Geertz (1989), Chaui (1995) e Werle et al. (2007).

Parte-se da compreensão de que a cultura escolar permite expandir a compreensão sobre a configuração interna da escola, a construção de valores, hábitos e saberes. Cultura escolar, termo cunhado por Julia (2001), pode ser definido como

um conjunto de normas que definem conhecimentos a ensinar e condutas a inculcar, e um conjunto de práticas que permitem a transmissão desses conhecimentos e a incorporação desses comportamentos; normas e práticas coordenadas a finalidades que podem variar segundo as épocas (finalidades religiosas, sociopolíticas e simplesmente de socialização). Normas e práticas não podem ser analisadas sem se levar em conta o corpo profissional dos agentes que são chamados a obedecer a essas ordens e, portanto, a utilizar dispositivos pedagógicos encarregados de facilitar sua aplicação, a saber, os professores primários e os demais professores. Mas, para além dos limites da escola, pode-se buscar identificar, em um sentido mais amplo, modos de pensar e de agir largamente difundidos no interior de nossas sociedades, modos que não concebem a aquisição de conhecimentos e de habilidades senão por intermédio de processo formais de escolarização. (p. 10)

No entanto, esta cultura escolar tem como fundamento a inserção e interação com a comunidade. Percebe-se a existência de um fio condutor perpassando a gestão escolar, suas práticas e processos, que é questão cultural da comunidade. Geertz (1989) define cultura como um padrão historicamente transmitido de significados encarnados em símbolos, um sistema de concepções herdadas, expressas em formas simbólicas por meio das quais os homens comunicam, perpetuam e desenvolvem seu conhecimento e atitudes em relação à vida. $\mathrm{O}$ autor defende que os grupos sociais criam uma variedade de códigos e símbolos, e as diferenças existentes entre os seres humanos e as culturas estão condicionadas aos diversos sistemas simbólicos constituídos.

O relato das entrevistadas expressa como a cultura de uma comunidade que se instituiu influenciada pela imigração alemã e italiana está impregnada na gestão da escola: 
G2: "Eu acho que um dos fatores é a cultura da comunidade onde a escola está inserida. Existe uma valorização pelo estudo, os alunos são assíduos, não faltam à aula. Isso contribui para que o processo deles seja rico. Acho que tudo isso tem a ver com o que falei lá no início, a valorização é cultural."

G4: "Outro aspecto é a cultura da comunidade. Existe um comprometimento de todos, porque também tem uma cobrança da comunidade, pelo fato de a comunidade ser pequena ela cobra, assim como ela ajuda, auxilia, valoriza, participa, mas também cobra para que o melhor seja feito. A comunidade está próxima, os professores que vem de outra cidade, sentem isso. A comunidade quer ver resultado, ela ajuda, valoriza, ela está próxima."

Botelho (2001) ressalta que a "cultura é definida como um sistema de signos e significados criados pelos grupos sociais. Ela se produz através da interação social dos indivíduos, que elaboram seus modos de pensar e sentir constroem seus valores, manejam suas identidades e diferenças e estabelecem suas rotinas (p. 2)".

Chaui (1995) chama a atenção para a necessidade de "alargar o conceito de cultura, tomando-o no sentido de invenção coletiva de símbolos, valores, ideias e comportamentos, de modo a afirmar que todos os indivíduos e grupos são seres e sujeitos culturais" (p. 81). Valoriza-se o patrimônio cultural imaterial, os modos de fazer, a tradição oral, a organização social de cada comunidade, os costumes, as crenças e as manifestações da cultura popular que remontam ao mito formador de cada grupo.

A religiosidade da comunidade alemã e italiana sempre foi algo latente na vida desses imigrantes que buscavam forças na religiosidade para suavizar a saudade da pátria, dos familiares. Embora não fosse posição unânime, a língua e as tradições culturais eram geralmente enfatizadas como elementos básicos para a vivência da religiosidade, através de orações e cânticos. Para Geertz (1989) a religião é um sistema de símbolos que atua no estabelecimento de poderosas, penetrantes e duradouras disposições e motivações nos homens através da formulação de conceitos de uma existência geral e vestindo essas concepções com tal aura de fatualidade que as disposições e motivações parecem singularmente realistas. O zelo, expresso e cultivado na religiosidade, reflete em ações comunitárias em prol da educação. $O$ vínculo tradicional igreja/escola/comunidade é um dado significativo nesse contexto. A preocupação dos colonizadores era que o lugar tivesse uma igreja e uma escola para os filhos. Com o relato é possível visualizar a tradição, a herança cultural e educacional do povo.

G1: "A tradição educacional, o povo alemão e o povo italiano valorizam a educação, dão muito valor a isso, a tradição religiosa. Em Nova Boa Vista o povo é muito religioso, desde os primeiros colonizadores, a preocupação era que o lugar tivesse uma Igreja e uma escola para os filhos. RDC1, 20 de outubro: Domingo, 10h, o pátio da lgreja Nossa Senhora dos Navegantes, cheio de famílias e crianças, afinal hoje é o dia da festa da escola, em que se festeja o dia do padroeiro da escola "Santos Anjos". Algo que chama a minha atenção é a participação efetiva das crianças, em alguns ritos como realização das leituras, preces, procissão do ofertório, $e$ o canto coral formado por crianças e adolescentes da escola." 
Vendo a necessidade de melhorias em todos os sentidos, no que se refere à educação, em 1956 o padre Davi Antônio Schwantz, então vigário dessa paróquia, começou uma campanha em prol da construção de uma escola melhor e que fosse dirigida por religiosas, pois se preocupava com a catequese bem como com a educação em geral. Para (EMSA, 1956),

havia uma escola de propriedade da comunidade, atendida pelo professor
Nicolau Wendling, auxiliado pela filha Eulália, ambos muito eficientes e
dedicados. O prédio dessa escola, contudo, tinha acomodações precárias
e inadequadas para atender as cem crianças que a frequentavam, razão
pela qual ele, com o auxílio da comunidade, começou a idealizar uma
escola pastoral. Menciona que, apesar de receoso, falou sobre a
construção de uma nova escola, após uma missa em 1956. Surpreendeu-
se com a empolgação das pessoas. Conforme o narrador, o Sr. João
Dalcin, que tinha uma filha religiosa, sugeriu que as Irmãs assumissem a
tarefa de educadoras. No entanto, outras pessoas queriam que o governo
criasse uma escola estadual, mas David percebeu que não havia condição
legal e que esse processo poderia demorar muito. A localização da escola
foi discutida em comunidade. Lembra que o sr. Afonso Barbian sugeriu que
a construção ficasse entre a cidade alta e a cidade baixa, a fim de uni-las.
Entretanto, David considerou que no alto moro ficaria esteticamente mais
bonita. Então essa ideia se efetivou quando o Sr. Jacob Wagner Sobrinho,
que era uma pessoa muito boa, equilibrada e um verdadeiro patriarca,
doou o terreno.

Cada escola tem uma personalidade própria, construída coletiva e historicamente por seus atores, no enfrentamento dos desafios. A escola é o resultado de uma teia de relações marcadas por crenças, valores, suposições, expectativas, emoções e sentimentos que determinam de que forma são tomadas as decisões. Como inovações são aceitas ou rejeitadas, como o trabalho é organizado e realizado e como ações educacionais se projetam no futuro ou permanecem reproduzindo a situação vigente. (Lück, 2011).

\section{Gestão na e da escola}

A discussão sobre a história da escola e a inter-relação com a cultura da comunidade leva à reflexão sobre a gestão como elemento que influencia as mudanças nas ações dos sujeitos, ao mesmo tempo em que os procedimentos de gestão estão sujeitos a determinadas compreensões emergidas de uma dada cultura. Para Lück (2008), "o conceito de gestão está associado à mobilização de talentos e esforços coletivamente organizados, à ação construtiva conjunta de seus componentes, pelo trabalho associado, mediante reciprocidade que cria um "todo" orientado por uma vontade coletiva" (p. 17).

A gestão da escola sob essa perspectiva tem como exigência lideranças competentes comprometidas com o exercício de práticas a partir de princípios educacionais democráticos, os quais possuem como referencial e orientação o trabalho coletivo em educação e as diretrizes e políticas educacionais públicas para a implementação do projeto político-pedagógico da escola: 
G4: "Mas para isso acontecer a equipe gestora precisa estar numa sintonia, em conjunto, portanto, a própria reunião da equipe gestora que acontece todas as segundas-feiras, é um momento de planejarmos e termos uma linguagem única, comum o grupo precisa sentir que existe uma linha única, para que os professores possam sentir isso e depois passem essa tranquilidade e segurança aos alunos."

A qualidade da educação aparece associada ao professor que busca aperfeiçoamento, que socializa com seus colegas o conhecimento:

G4: "Um professor que estuda, lê, se aprofunda e socializa seus conhecimentos com os colegas de trabalho, também vai para sala de aula com uma nova dinâmica, com instrumento novo de trabalho."

G2: "A qualidade também passa pelo conhecimento. Construir conhecimento com o aluno só se consegue com disciplina, com a dinamicidade da troca, do saber ouvir, do respeito pelo diferente lá na sala de aula. Eu acho que a qualidade se constrói dessa maneira."

G3: "Penso que a qualidade da educação passa pelo diálogo, pelo comprometimento em achar uma forma de melhorar. Às vezes não se conseguem as coisas de uma hora para outra, mas a gente está caminhando para que as coisas sempre venham a se desenvolver da melhor maneira possível."

Evidencia-se o pressuposto de os pais desejam que os conhecimentos, as habilidades e os valores tenham serventia para a vida, ou seja: desejam uma escola em que os alunos estejam motivados para estar nas aulas e se envolvam com afinco nas atividades da classe. Portanto, há uma preocupação da equipe gestora e dos professores em proporcionar momentos de formação para as famílias:

G2: "Temos a preocupação de sempre promover momentos de formação também para as famílias e é preciso cuidado para atender as expectativas dos pais para não afastá-los da escola."

RDC5, 21 de dezembro de 2013: "Ruas trancadas, arquibancada repleta de pessoas para acompanhar os preparativos do espetáculo de natal. A temática central foi o natal no Brasil. Uma passagem pelas diferentes culturas regionais com a participação de talentos musicais e artísticos da comunidade local."

Para G2 e G3, a qualidade da educação passa pelo conhecimento, pela dinamicidade da troca de saberes, pelo diálogo, pelo comprometimento e pela busca constante da excelência pedagógica. A qualidade da educação, entendida como desenvolvimento integral das potencialidades humanas, é o desenvolvimento das habilidades sociais, físicas, afetivas, o cultivo dos valores, da espiritualidade, 0 envolvimento com a comunidade:

G4: "Acho que para nós é o desenvolvimento integral das potencialidades humanas, não é só o desenvolvimento das habilidades cognitivas, mas também o desenvolvimento das habilidades sociais, físicas, afetivas, os 
valores, a espiritualidade, o envolvimento com a comunidade, isso não deixa de ser algo que gera a qualidade na educação. Considerando a própria sala de aula uma pequena comunidade de aprendizagem, penso que ali, onde se desenvolve não somente a capacidade de aprender, mas sim as outras capacidades, de forma integral, isto eu penso que é qualidade."

RDC7, 30 de setembro de 2013: "É interessante o cuidado, a organização dos estudantes, orientados pelos professores e direção que acompanha o embarque das crianças. Em questão de dez minutos a escola perde a dinamicidade."

Para a G1 o conceito de qualidade está vinculado ao crescimento pessoal do aluno, para que esse possa se tornar um bom cidadão, atuante e participativo na sociedade e na comunidade local.

G1: "Qualidade é quando você vê o rendimento do aluno, o aproveitamento, o seu avanço, é ver o seu crescimento pessoal, isso para mim é qualidade. As notas são claro importantes, mas o mais importante é o que eles levam daqui para vida na sociedade; isto é qualidade para mim. Formar um aluno e depois vê-lo atuando na comunidade, tendo condições de ser um bom cidadão, participativo, atuante, isso é qualidade. Quando o aluno sai da escola (termina o curso fundamental) a gente fica sabendo, os valores que ele leva, a gente acaba acompanhando, pois ele volta feliz com o seu sucesso, isso é qualidade, não é só nas notas, mas sim os valores que ele leva."

Algo que se desvelou na EMSA é o planejamento conjunto que acontece entre os professores, contando uma participação dos alunos. É um processo que ocorre na escola já há algum tempo. Semanalmente o corpo docente e a equipe gestora estudam, refletem sobre algo vinculado à prática pedagógica. Posteriormente acontece o planejamento coletivo com os professores das diferentes áreas do conhecimento, construindo comunidades de aprendizagem entre professores e alunos:

G3: "Considero é o planejamento coletivo, que acontece nas terças-feiras, um ganho, por acontecer uma troca entre os participantes. Um processo que também ajuda para a qualidade da educação na Santos Anjos é a formação continuada nas mais diversas áreas do conhecimento. Depois de cada atividade realizamos a avaliação de como foi. Então esse tempo que se tem, e uma conquista e ele é um diferencial."

A G2 aborda como relevante a metodologia de projetos, que se vincula ao programa A união faz a vida3, que acontece na escola desde 2001, com o objetivo de construir e vivenciar atitudes e valores de cooperação e cidadania por meio de práticas de educação cooperativa, contribuindo para a educação integral de crianças e adolescentes em âmbito nacional. Consiste numa metodologia que exige uma dinâmica diferenciada à gestão da escola, pois os professores necessitam pensar, refletir, planejar, executar e avaliar os projetos com a participação efetiva dos alunos. Utiliza uma linguagem própria, como

3 O programa $A$ união faz a vida tem inspiração nos princípios do cooperativismo e é disseminado pelo Banco Sicredi.

Regae: Rev. Gest. Aval. Educ.

Santa Maria

v. 8

n. 17

Pub. contínua 2019

p. $1-16$ 
comunidade de aprendizagem, expedição investigativa, assembleias, questões norteadoras, pergunta exploratória, etc. (Sicredi, 2016). Como resultado do processo, espera-se um aluno mais participativo, mais curioso, um pesquisador, uma pessoa mais cidadã.

G2: "É um momento em que os professores podem planejar suas atividades de forma interdisciplinar, pois estão todos presentes para dialogar e trocar ideias. Escolhe-se sempre um conteúdo de uma das áreas do conhecimento que possa ser o ponto de partida para uma investigação e depois as demais áreas contribuem com seus conhecimentos específicos para desenvolver os projetos. Isso exige diálogo constante e planejamento conjunto, levando em conta sempre o conhecimento que o aluno já tem sobre o assunto e o que ainda gostaria de saber sobre ele. Veja que o diferencial é a participação do aluno, o projeto nasce do interesse e da participação do aluno."

A coordenação pedagógica tem um papel significativo nesse processo, de pensar, de organizar, acompanhar e assessorar o processo pedagógico. Outro processo que também é considerado relevante para a qualidade da educação na EMSA é a formação continuada dos professores. Esta formação acontece na escola, mensalmente às segundas-feiras no turno da noite, com todos os professores. Acontece por meio de leituras e estudos para reflexão das experiências educativas. Além de permitir um planejamento coletivo, nestes momentos de formação continuada sempre é estudado algum aspecto teórico, debatendo-se um texto, um assunto relevante para suprir uma necessidade da escola - o que se mostra como um diferencial.

Pensa-se que alguns aspectos presentes aqui podem favorecer os resultados do Ideb o que, em momento algum, se apresentou como objetivo da escola: configura-se como uma escola dinâmica, a assiduidade e o fato dos alunos gostarem de vir para a escola, as aulas de reforço de Matemática e Português; a sala de recursos, a parceria com os pais; o atendimento diferenciado às crianças com dificuldades de aprendizagem.

A presença da comunidade na escola, em especial dos pais, acompanhando e avaliando a qualidade da educação na EMSA, é uma sintonia, nesse diálogo, com a maioria das famílias:

G2: "A maioria dos pais valoriza a escola; eles delegam a autoridade para a escola. Claro que também há os que não aparecem. A gente chama, chama e não aparecem, mas são poucos. A grande maioria dos pais delega a autoridade para escola, porque acreditam no nosso trabalho. A escola está certa, se ela chama os pais é porque quer o melhor para seus filhos, ou seja, o que diretora está dizendo, o que a coordenação está dizendo, isso vale lá em casa, ele vai corresponder."

No relato das entrevistadas, percebe-se que a metodologia de projetos, adotada pela gestão da escola, auxilia para atingir o objetivo da EMSA, que é proporcionar ao educando a formação necessária ao desenvolvimento de suas potencialidades, incentivando a pesquisa, a construção do conhecimento e o exercício consciente da cidadania. 


\section{Considerações finais}

Constatou-se que, os resultados do Ideb na Escola Municipal Santos Anjos, relacionam-se com a cultura da comunidade e a cultura da escola associadas às práticas da gestão nela implantadas. Em relação à variável cultura da comunidade e da escola, destacam-se como aspectos que contribuíram para a qualidade do ensino: a história, a herança cultural, o relacionamento entre família e escola, a valorização dos alunos, o gostar da escola, a razão de ser da escola, os valores, as diretrizes, os princípios e a presença das religiosas.

No que diz respeito à herança cultural, cada escola apresenta uma cultura diversa, que marca a qualidade do seu desempenho e, de certo modo, afeta seus resultados educacionais. A EMSA está ligada a um conjunto de tradições, conhecimentos, crenças, que são passados de geração a geração, através do relato de histórias, discursos, atitudes. Na EMSA a herança cultural é algo latente e que perpassa a gestão da escola. $O$ vínculo tradicional igreja, escola ecomunidade é um dado neste contexto. A influência da herança cultural, a memória histórica ou a memória coletiva, fundamenta a própria identidade do grupo ou comunidade, composta pelas lembranças vividas pelo indivíduo ou que the foram repassadas, mas que não pertencem somente a ele e, sim, são entendidas como propriedade de uma comunidade, de um grupo. O vigor expresso e cultivado no cooperativismo e na religiosidade reflete-se em ações comunitárias em prol da educação, porque a cultura é definida como um sistema de signos e significados criados pelos grupos sociais. Ela se produz através da interação social dos indivíduos, que elaboram seus modos de pensar e sentir, constroem seus valores, manejam suas identidades e diferenças e estabelecem suas rotinas.

Quanto ao relacionamento entre família e escola, a integração família e escola foi identificada com um fator de impacto nos resultados de aprendizagem dos alunos. $\mathrm{Na}$ escola em que os pais participam mais, os alunos aprendem mais. Isso porque, mediante essa participação, os pais demonstram que valorizam a escola e a aprendizagem que ela proporciona. A interação entre escola, família e comunidade torna-se um princípio na medida em que as relações construídas nessa interação têm, em sua singularidade, ideais comuns e a partilha do trabalho e da responsabilidade na educação das crianças e dos jovens.

Os alunos percebem que são valorizados e essa valorização ocorre na medida em que são reconhecidos com suas diferenças individuais que não são apenas aceitas como também reconhecidas por apresentar demandas, sendo encaminhados para atendimentos personalizados. A qualidade da educação passa pelo conhecimento, pela dinamicidade da troca de saberes, do respeito pelo diferente, pelo diálogo, pelo comprometimento e pela busca constante da excelência pedagógica. A valorização do aluno gera a qualidade da educação, entendida como desenvolvimento integral das potencialidades humanas, o desenvolvimento das habilidades sociais, físicas, afetivas, o cultivo dos valores, da espiritualidade.

Gostar de ir à escola e ter vontade de frequentá-la é resultado de todo um conjunto de condições, tais como: a convivência com os amigos e colegas, o relacionamento interpessoal com os professores e equipe gestora, enfim, sentir-se feliz na escola. A EMSA é um espaço onde se prima pela qualidade física e humana dos seus ambientes de socialização e aprendizagem, caracterizados pelo acolhimento afetuoso e lúdico, pela 
segurança, o que favorece relações de proximidade, respeito mútuo e observância das individualidades. Com essa preocupação a EMSA concilia o conteúdo das disciplinas à educação dos sentimentos, através de atividades que trabalham com valores, a cooperação, a solidariedade, a capacidade imaginativa e criativa de seus alunos e o afeto, proporcionando a eles um crescimento cognitivo e social, observando limites para uma vida em sociedade.

A formação dos alunos e sua aprendizagem são consideradas e assumidas na EMSA como a razão de ser da instituição, de seus profissionais e o foco de todas as suas decisões e ações. A aprendizagem é considerada como um valor inerente ao modo de ser e de fazer da escola e vivenciada por todos em seu trabalho. Isto é, a aprendizagem supera as propostas pedagógicas da escola e de seu discurso, constituindo-se como um espírito que se respira e se sente em todas as práticas escolares. Nesse caso, o importante não são as notas que o aluno obtém em avaliações, mas o que aprende e incorpora como um valor em sua vida.

Percebeu-se que a comunidade escolar da EMSA age de forma alinhada com valores, diretrizes, princípios, objetivos, metas educacionais claros, continuamente discutidos e analisados. Há uma preocupação em preservar a excelência de qualidade educacional. Nota-se que os valores, os princípios e objetivos educacionais são definidos claramente e conhecidos por todos, sendo continuamente reexaminados por avaliações do trabalho realizado. Esse ideário se faz presente no projeto pedagógico da unidade de ensino, sendo explicitadas as implicações da ação de todos, para que sejam colocadas em prática. Dessa forma, ao afirmar seus objetivos a EMSA busca distinguir-se como uma escola de excelência, aliando a reflexão da equipe de trabalho à realização de suas propostas. A EMSA busca ser excelente naquilo que faz, formando cidadãos atuantes no contexto em que vivem.

Em relação à variável gestão na e da escola, destacam-se aspectos que contribuíram para a qualidade do ensino na EMSA, tais como: a equipe gestora, a qualidade da formação docente, o planejamento coletivo, a excelência pedagógica, 0 processo dialógico, o programa $A$ união faz a vida, o clima organizacional e um ambiente acolhedor.

A equipe gestora é unida, comprometida e tem clareza da missão, da visão e dos valores educacionais, de modo a manter sua equipe focada por unidade de trabalho e a busca constante pela excelência pedagógica. Acredita-se que também seja um processo relevante a valorização do ser humano, o respeito entre professores e alunos, dos funcionários, a organização institucional. Existe uma preocupação do trabalho da equipe gestora, que sempre está se organizando, planejando, discutindo, refletindo e avaliando, com antecedência, todos os envolvidos nesse processo. Um bom ambiente de trabalho, o planejamento desse grupo, certa clareza dos objetivos, o trabalho em equipe, 0 comprometimento e entrosamento do corpo docente são fatores que impactam nos resultados da escola.

Um fator que desafia e preocupa a equipe gestora da escola é a rotatividade dos professores, algo que acontece com frequência. Há uma preocupação da equipe gestora em proporcionar condições de aprendizagem aos alunos com determinadas dificuldades de aprendizagens. Para isso existem atendimentos especializados e uma estrutura que possa atender as diferentes lacunas, sendo elas de aprendizagem ou até mesmo físicas. 
Trata-se de salas específicas com recursos próprios, para onde são encaminhados os estudantes com dificuldades de aprendizagem, sendo atendidos por profissionais com habilitação específica.

Os professores da escola buscam constante aperfeiçoamento para novos processos e metodologias de trabalho, de modo a torná-lo mais estimulante para os alunos. Os professores da EMSA vivenciam práticas participativas, em que aprendem nas situações de trabalho, compartilham com os colegas conhecimentos, metodologias e dificuldades, discutem e tomam decisões sobre o projeto pedagógico curricular, sobre as relações sociais internas, sobre as práticas de avaliação. Esse modo de funcionamento da organização e da gestão na EMSA considera a escola uma comunidade de aprendizagem, ou seja, uma comunidade democrática, aberta, de ação e reflexão. Portanto, é a qualidade da formação dos docentes, o sentimento de pertença de trabalhar na escola e o comprometimento no desempenho do seu trabalho que contribuem para os resultados alcançados pela escola.

Algo que é relevante na EMSA é o planejamento conjunto que acontece entre os professores com a participação efetiva dos estudantes. É um processo que vem acontecendo na escola já há algum tempo. Semanalmente, o corpo docente e a equipe gestora estudam, refletem sobre certo aspecto vinculado à prática pedagógica. Posteriormente, acontece o planejamento coletivo semanal com os professores das diferentes áreas do conhecimento, num período de quatro horas; durante esse planejamento os alunos participam de oficinas com outros professores e profissionais da escola. A coordenação pedagógica tem um papel preponderante nesse processo de pensar, de organizar, de acompanhar e assessorar o processo pedagógico.

Destaca-se que o processo de formação continuada dos professores proporcionado pela EMSA dá-se pelo planejamento coletivo semanal de quatro horas, a reunião de estudos mensal nas segundas-feiras à noite com todos os professores da escola, além da busca individual pelo aperfeiçoamento. A excelência pedagógica concretiza-se nos projetos inovadores e nas ações conjuntas do corpo docente e da equipe gestora. Isso está articulado com o PPP e com as novas demandas que são atendidas com compromisso ético. Mantêm-se constantes investimentos na formação continuada dos profissionais de todas as áreas de atendimento à comunidade educativa, nos materiais pedagógicos, nos espaços de socialização e interação de saberes.

A EMSA estimula e proporciona ações pelas quais acontece o processo dialógico na comunidade escolar entre alunos, professores, funcionários, pais, equipe gestora e comunidade local. A escola como um processo aberto e dialógico de comunicação, onde acontece a troca de informações, ideias, expectativas, opiniões, conhecimentos, sentimentos e impressões, pelos quais se constrói um entendimento comum, que permite a unidade de propósitos e ações, o estabelecimento de sinergia entre as pessoas, a integração de seu trabalho.

A metodologia de projetos adotada a, aproximadamente, quinze anos pela EMSA, exige uma dinâmica diferenciada à gestão da escola, pois professores necessitam pensar, refletir, planejar, executar e avaliar os projetos com a participação efetiva dos alunos. É cultivado entre os profissionais da EMSA o respeito mútuo associado a um sentido de 
responsabilidade, comprometimento e colaboração pela melhoria conjunta de seu trabalho. Os professores procuram integrar seu trabalho com o dos colegas, além de compartilhar suas inovações e boas experiências para que também aprendam com elas.

A EMSA oferece um ambiente acolhedor, organizado, limpo e estimulador. Escolas em que os alunos mais aprendem e se desenvolvem cuidam continuamente de sua limpeza e organização, da manutenção de seu espaço e de seus materiais. Também zelam pela disciplina como uma circunstância de respeito recíproco entre professores e alunos, alunos e alunos, professores e funcionários, gestores e toda a comunidade escolar. A respeito da disciplina, destaca-se a importância de contínua orientação para o relacionamento dos alunos entre si, a fim de se evitarem brincadeiras de mau gosto ou agressivas, humilhações, agressões físicas ou verbais, que geram um sentimento de insegurança na escola.

\section{Referências}

AFONSO, Almerindo Janela. Protagonismos instáveis dos princípios de regulação e interfaces público/privado em educação. Revista Educ. Soc., Campinas, v. 31, n. 113, 2010, p. 1137-1156.

AGUIAR, Clarissa Maria Bezerra de. Gestão democrática da educação e o papel dos conselhos escolares: o caso do município de Olinda. [S.I.]. 2009.

BARDIN, Laurence. Análise de conteúdo. São Paulo: 70, 2011.

BODGAN, Robert C; BIKLEN, Sari Knopp. Investigação qualitativa em educação: uma introdução à teoria a aos métodos Porto: Porto, 1994.

BOTELHO, Isaura. Dimensões da cultura e políticas públicas. São Paulo em Perspectiva, São Paulo, v. 15, n. 2, 2001.

BRANDÃO, Carlos Rodrigues. A pergunta a várias mãos: a experiência da pesquisa no trabalho do educador. São Paulo: Cortez, 2003.

BRASIL. Censo escolar 2013. Disponível em http://portal.inep.gov.br/basica-censo. Acesso em 2 abr. 2016.

BRASIL. Índice de desenvolvimento da educação básica. Disponível em http://www.inep.gov.br/. Acesso em 2 out. 2016.

CALDAS, Edla Cristina Rodrigues; PINHEIRO, Maria das Graças Sá Peixoto. Políticas públicas e gestão escolar: a participação da comunidade em escolas do ensino fundamental, zona leste de Manaus. SIMPÓSIO BRASILEIRO DE POLÍTICA E ADMINISTRAÇÃO DA EDUCAÇÃO, 24, 2009. Anais ... Vitória: Ufes, 2009. Disponível em http://www.anpae.org.br/congressos antigos/simposio2009/221.pdf. Acesso em 22 abr. 2016.

CHAUI, Marilena. Cultura política e política cultural. Estudos Avançados, São Paulo, v. 9, n. 23, 1995, p. 71-84.

CHIZZOTTI, Antônio. A pesquisa qualitativa em ciências humanas e sociais: evolução e desafios. Revista Portuguesa de Educação, v. 16, n. 2, 2003, p. 221- 236.

CORREIA, José Alberto. La evaluocracia: el papel de la evaluación en la legitimación y reconstrucción institucional de la educación: avances en supervisión educativa. Revista de la Asociación de Inspectores de Educación de España, n. 13, 2010a, p. 35-50.

CORREIA, José Alberto. Paradigmas e cognições no campo da administração educacional: das políticas de avaliação à avaliação como política. Revista Brasileira de Educação, v. 15, n. 45, 2010b, p. 456-592. 
DANTAS, Cátia Verônica Nogueira. Plano de trabalho gestor: e o efetivo desenvolvimento das atividades de gestão escola. Salvador: Ueba, 2011. 86f. Dissertação (mestrado em Educação e Contemporaneidade). Programa de Pós-Graduação em Educação e Contemporaneidade. Universidade do Estado da Bahia.

DUBLANTE, Carlos André de Sousa. Gestão escolar: fundamentos e práticas em escolas municipais de São Luís/MA. São Luís: UFMA, 2009. 163f. Dissertação (mestrado em Educação). Programa de Pós-Graduação em Educação, Universidade Federal do Maranhão. São Luís.

E. E. E. M. ANTÔNIO MATHIAS ANSCHAU. Nova Boa Vista: histórias e memórias. Nova Boa Vista: Prefeitura Municipal, 2012.

ESCOLA MUNICIPAL SANTOS ANJOS. Projeto político-pedagógico. Nova Boa Vista: Prefeitura Municipal, 2006.

ESCOLA MUNICIPAL SANTOS ANJOS. Registro da fundação da escola. Nova Boa Vista: Prefeitura Municipal, 1956.

FERNANDES, Cláudia de Oliveira; FREITAS, Luiz Carlos de. Indagações sobre currículo: currículo e avaliação. Brasília: MEC, 2007.

FONSECA, Marília. O Banco Mundial como referência para a justiça social no terceiro mundo: evidências do caso brasileiro. Revista da Faculdade de Educação, 1998. Disponível em $\quad$ http://www.scielo.br/scielo.php?script=sci arttext\&pid=S010225551998000100004. Acesso em 10 dez. 2016.

FREITAS, Dirce Nei Teixeira de. A avaliação da educação básica no Brasil: dimensão normativa, pedagógica e educativa. Campinas: Autores Associados, 2007.

FREITAS, Dirce Nei Teixeira de. Avaliação da educação básica e ação normativa federal. Cadernos de Pesquisa, v. 34, n. 123, 2004, p. 663-689.

FREITAS, Luiz Carlos de et al. Avaliação educacional: caminhando pela contramão. Petrópolis: Vozes, 2012.

GARCIA, Ana Lúcia. Gestão da escola, qualidade do ensino e avaliação externa: desafios na e da escola. Marília: Unesp, 2010. 98f. Dissertação (mestrado em Educação). Programa de Pós-Graduação da Faculdade de Filosofia e Ciências.

GEERTZ, Clifford. A interpretação das culturas. Rio de Janeiro: LTC, 1989.

JULIA, Dominique. A cultura escolar como objeto histórico. Revista Brasileira da História da Educação, n. 1, 2001, p. 9-43.

LIBÂNEO, Jose Carlos. Educação escolar: políticas, estruturas e organização. São Paulo: Cortez, 2012.

LIVRO TOMBO. Paróquia Nossa Senhora dos Navegantes de Nova Boa Vista, 1956.

MARTINS, Gilberto de Andrade. Estudo de caso: uma estratégia de pesquisa. São Paulo: Atlas, 2008.

MARTINS, Sidnéia Macarini. O papel do coordenador pedagógico na melhoria da educação básica: uma reflexão sobre o uso da avaliação externa. Presidente Prudente: Unoeste, 2010. 94f. Dissertação (mestrado em Ciências Humanas). Universidade do Oeste Paulista.

MAUÉS, Olgaíses Cabral. Os organismos internacionais e as políticas públicas educacionais no Brasil. In: GONÇALVEZ, L. A. O. Currículo e políticas públicas. Belo Horizonte: Autêntica, 2003, p. ??-??. 
ROSA, José Paulo da. Gestão escolar: um modelo para a qualidade Brasil e Coreia. Porto Alegre: PUCRS, 2011. 278f. Tese (doutorado em Educação). Programa de PósGraduação em Educação. Pontifícia Universidade Católica do Rio Grande do Sul.

SANTOS, Wilson da Silva. O caráter organizacional e cultural da gestão escolar: breves anotações, 2009.

SILVA, Maria Abádia da. Intervenção e consentimento: a política educacional do Banco Mundial. Campinas: Autores Associados: São Paulo, 2002.

SOUZA, Sandra Zákia Lian de; OLIVEIRA, Romualdo Portela de. Políticas de avaliação da educação e quase mercado no Brasil. Rev. Educ. Soc., Campinas, v. 24, n. 84, 2003, p. 873-895. Disponível em http://www.cedes.unicamp.br. Acesso em 22 abr. 2014.

SZYMANSKI, Heloisa; ALMEIDA, Laurinda R; PRANDINI, Regina C. A. R. A entrevista na pesquisa em educação: a prática reflexiva. Brasília: Liber Livro, 2011.

TRIVIÑOS, Augusto Nibaldo Silva. Introdução à pesquisa em ciências sociais: a pesquisa qualitativa em educação. São Paulo: Atlas, 1987.

WERLE, Flávia Obino Correa (org.). Avaliação em larga escala: foco na escola. São Leopoldo: Oikos/Brasília: Líber Livro, 2010.

WERLE, Flávia Obino Corrêa. Avaliação em larga escala: questões polêmicas. Brasília: Líber Livro, 2012.

WERLE, Flávia Obino Corrêa; BRITTO, Lenir Maria Trindade Sá; COLAU, Cinthia Merlo. Espaço e história das instituições escolares. Diálogo Educ., Curitiba, v. 7 n. 22, 2007, p. 147-163.

WIEBUSCH, Eloisa Maria. Avaliação externa: um caminho para a busca da qualidade da educação. Porto Alegre, 2011.

Rosangela Fritsch é doutora em Educação pela Universidade do Vale do Rio dos Sinos, professora e pesquisadora dos Programas de Pós-Graduação em Educação e Gestão Educacional da Unisinos.

Orcid: https://orcid.org/0000-0002-0630-3649.

Endereço: Rua Pastor Schlieper, 138 - 93042-180 - São Leopoldo - RS - Brasil.

E-mail: rosangelaf@unisinos.br.

Angela Thums é estudante no curso de doutorado em Educação na Universidade do Vale do Rio dos Sinos. Trabalha no Colégio Notre Dame de Passo Fundo/RS. Endereço: Avenida Brasil Oeste, 952 - 99025-003 - Passo Fundo - RS - Brasil. Orcid: https://orcid.org/0000-0002-5447-2834.

E-mail: angela@notredame.org.br.

Recebido em 31 de julho de 2018.

Aceito em 7 de outubro de 2018.

(c) (i) 